Article

\title{
The Prostate Clinical Outlook (PCO) Classifier Application for Predicting Biochemical Recurrences in Patients Treated by Stereotactic Body Radiation Therapy (SBRT)
}

\author{
Seong K. Mun ${ }^{1,2}$, Jihwan Park ${ }^{2,3}{ }^{1}$, Anatoly Dritschilo ${ }^{4}$, Sean P. Collins ${ }^{4}$, Simeng Suy ${ }^{4}$, \\ In Young Choi ${ }^{3}$ and Mi Jung Rho $1,3, * \mathbb{D}$ \\ 1 Arlington Innovation Center, Virginia Tech, 900 N Glebe Road, Arlington, VA 22203, USA; \\ munsk@osehra.org \\ 2 Open Source Electronic Health Record Alliance, 1934 Old Gallows Road Suite 420, Vienna, VA 22182, USA; \\ bosoagalaxy@gmail.com \\ 3 Department of Medical Informatics, College of Medicine, The Catholic University of Korea, 222, \\ Banpo-dong, Seocho-gu, Seoul 06591, Korea; iychoi@catholic.ac.kr \\ 4 Department of Radiation Medicine, Georgetown University Hospital, 3800 Reservoir Rd. NW, Washington, \\ DC 20007, USA; dritscha@georgetown.edu (A.D.); SPC9@gunet.georgetown.edu (S.P.C.); \\ Simeng.Suy@gunet.georgetown.edu (S.S.) \\ * Correspondence: rhomijung@gmail.com
}

Received: 18 June 2018; Accepted: 7 August 2018; Published: 12 September 2018

\begin{abstract}
Background: Prostate cancer risk classifiers have been used for predicting surgical and radiation therapy outcomes; however, a classifier for predicting biochemical recurrence (BCR) in patients undergoing stereotactic body radiation therapy (SBRT) is not available. We attempted to develop a model that creates a risk classifier to predict BCR in patients considering SBRT. (2) Methods: We studied the outcomes of 809 patients treated with SBRT between August 2007 and November 2016. We used Cox regression analysis with time to BCR as the outcome to develop a model that calculates a prostate clinical outlook (PCO) score based on age at diagnosis, clinical-radiological staging, and a modified risk level. We then created the PCO classifier application, which uses the model we created to categorize patients into risk groups based on multiple factors. We assessed the concordance index (c-index) to determine the accuracy of the PCO classifier application and compared the results to the D'Amico and Kattan nomogram classifications. (3) Results: The calculated PCO scores ranged from 0 to 156 points. The PCO classifier application categorized patients into three risk-groups, with 5-year BCR-free survival rates of $98.3 \%$ for low risk $(n=137), 95.4 \%$ for intermediate risk $(n=570)$, and $86.4 \%$ for high risk $(n=102)$. We demonstrated the improved prognostic power of the PCO classifier application, with a c-index of 0.75 (training set) and 0.67 (validation set); the c-index of the Kattan nomogram was 0.62 and 0.63 , respectively, and that of the D'Amico classifier was 0.64 and 0.64, respectively. (4) Conclusions: The PCO classifier application is a predictive tool for employing readily available clinical parameters to stratify prostate cancer patients and to predict the probability of BCR after SBRT.
\end{abstract}

Keywords: biochemical recurrence; CyberKnife; nomogram; prostate cancer; risk classification; stereotactic body radiation therapy; predictive analytics

\section{Introduction}

As the most common solid malignancy diagnosed in men, prostate cancer was the second most common cause of cancer death in 2016 [1,2]. However, advances in radiation oncology have led 
to the development of effective therapies for clinically localized prostate cancer. Stereotactic body radiation therapy (SBRT) is delivered in large fractions of highly conformal radiation therapy. It is designed to deliver a very precise type of external radiation treatment and to provide optimized results while minimizing side effects. SBRT is a safe and effective treatment for clinically localized prostate cancer. Compared with surgery, it is an outpatient procedure that does not require general anesthesia or hospitalization, and it can be completed within four to five sessions. There are diverse benefits: no pain; minimal invasiveness; little or no recovery time; only five treatments instead of 40, the latter being typical of other forms of radiation therapy; few or reduced side effects; and speed, convenience, and effectiveness [3]. Such treatments are believed to be radiobiologically more effective in treating prostate cancers than the conventional low-dose fractions commonly used for prostate cancer radiotherapy $[4,5]$. In addition, SBRT treatment of localized prostate cancer has been reported as safe, and it offers excellent local control, as determined by freedom from biochemical recurrence $(\mathrm{BCR})$ in patients presenting with low- and intermediate-risk cancers [6-8].

Risk assessments tools have been developed for predicting surgical and radiation therapy outcomes following standard prostate cancer treatment (i.e., D'Amico [9], Kattan nomogram [10], the University of California, San Francisco Cancer of the Prostate Risk Assessment (CAPRA) score [11], and the Candiolo classifier [12]). Although these risk assessments have been developed for predicting outcomes, these assessments have not been applied for use in patients treated with SBRT.

SBRT has been proven effective for the treatment of low- and intermediate-risk prostate cancer patients, who are the dominant recipients of SBRT treatment. However, there is yet to be a classifier that can be applied to predict BCR of patients treated with SBRT.

Therefore, we developed a prostate clinical outlook (PCO) classifier application that provides information on predicted BCR, specifically for patients electing to undergo prostate cancer treatment with SBRT. We have also proposed a prostate clinical outlook visualization system (PCOVS) based on the PCO classifier application [13].

\section{Materials and Methods}

Using Cox regression analysis, with time to BCR as the outcome for prostate cancer patients who underwent SBRT, a model was developed that calculates a PCO score based on (1) age at diagnosis, (2) clinical-radiological staging, and (3) the modified risk level based on a combination of pretreatment prostate specific antigen (PSA) and the Gleason score.

We studied the outcomes of 809 prostate cancer patients at MedStar-Georgetown University Hospital's Department of Radiation Medicine between August 2007 and November 2016. They were treated with SBRT after being diagnosed with prostate cancer and undergoing follow-up management. The patients were seen for follow-up examinations and blood sample collection at 3-month intervals for 2 years and then 6-month intervals for the remaining 3-year follow-up period.

We focused on BCR at 5 years after SBRT. The patients were enrolled in an IRB (Institutional review board)-approved study (\#12-1175). The analysis was performed on de-identified, HIPAA-compliant data.

The PCO score was calculated using a nomogram. The three predictors we used for the PCO classifier application were as follows: (1) age at diagnosis, (2) clinical-radiological staging, and (3) modified risk level, which is the combination of pretreatment PSA and the Gleason score. These were selected and modified based on one physician's comments and fed into the application.

We used age, clinical-radiological staging, and modified risk level as independent variables in the regression analysis. For input into our PCO classifier application, patients were grouped into four age categories: 59 and under, 60-69, 70-79, and over 80 years. After an initial data review of tumor staging, only three patients presented with T3 tumors; a number were considered inadequate for separate analysis. Therefore, based on standard $\mathrm{t}$-stage classification [14], the patients were assigned into the following groups: T1 (T1a, T1b, T1c), T2a, T2b, and T2c + T3. Recent studies have categorized a Gleason 7 tumor as two types: $7 \mathrm{a}$ (primary $3+$ secondary 4$)$ and $7 \mathrm{~b}(4+3)[4,15]$. Thus, the PCO classifier application divided the Gleason score into four grades (Table 1). Pretreatment PSA scores 
were divided into three categories: $\leq 10.0 \mathrm{ng} / \mathrm{mL},>10.0$ and $\leq 20.0 \mathrm{ng} / \mathrm{mL}$, and $>20.0 \mathrm{ng} / \mathrm{mL}$ (Table 1 ). We used a modified risk level based on a combination of the Gleason score and pretreatment PSA (Table 1) [16] and determined five classifications for the modified risk level.

Using a total score range based on BCR-free survival rate at 4 years, the patients were classified into one of three groups: $99 \%, 90 \%$, and $80 \%$. We determined three risk-groups based on patient distribution and the range of the total score (Appendices). Finally, the three risk-groups were validated by physician comments. The BCR-free survival rate at 4 years was used to calculate PCO scores. Because prostate cancer treated with SBRT has the lowest recurrence rate, there were not enough BCR rates to calculate the risk score using the BCR-free survival rate at 5 years.

To determine the accuracy of the PCO classifier application, we computed the concordance index (c-index). The $95 \%$ CI of the c-index was calculated by K-folder cross-validation. K-folder cross-validation is an effective validation procedure for classification $[17,18]$; we used 5-folder cross-validation in this study. To obtain balanced statistical power, we divided the data into two sets: training and test data [18]. We matched seven training datasets $(n=570)$ to four test datasets $(n=239)$. In addition, the PCO classifier application and classifications according to the $\mathrm{D}^{\prime}$ Amico and Kattan nomogram risk groups were compared.

Survival data analyses were used to find the disease-free survival rates. We used the Kaplan-Meier estimator and Cox multivariable regression analysis to determine the risk factors significantly associated with BCR.

In this study, we used the American Society of Therapeutic Radiology and Oncology (ASTRO) definitions for BCR [19]. ASTRO defines BCR as the midpoint between the PSA nadir and the first of three consecutive rises in PSA level [20]. According to the Phoenix definition, BCR is an increase of at least $2 \mathrm{ng} / \mathrm{mL}$ from the nadir PSA [21]. It has been reported that using the Phoenix definition resulted in substantially lower estimates of BCR at 5 years and substantially higher estimates of BCR at 10 years, compared with the ASTRO definition [22]. Using the ASTRO definition resulted in better outcomes for up to 7 years after radiotherapy [23]. We focused on BCR at 5 years. Therefore, for our analyses, BCR was defined according to the ASTRO definition [22] and physician comments: the midpoint between PSA nadir and the first of three consecutive rises in PSA of at least $0.5 \mathrm{ng} / \mathrm{mL}$.

The data were analyzed using $R$ packages (R language; R V3.3.1; 21 June 2016) [24] and SPSS, version 18.0.

\section{Results}

\subsection{Patients}

The 809 patients' ages at diagnosis ranged from 44 to 100 years (Table 1), with $43.8 \%$ in the $70-79$-year-old age range and $38.7 \%$ of the patients in the $60-69$-year-old age range. The mean patient age was 70 years. The patients presenting with $\mathrm{T} 1$ tumors (T1b and T1c) comprised $66.4 \%$ of the study population. The patients with T2a comprised $16.7 \%$ of the study population. Based on the Gleason score, $37.3 \%$ of the patients had a low-risk disease, and $36.1 \%$ of the patients had a favorable intermediate $(7=3+4)$ risk. A total of $18 \%$ of the patients had an unfavorable intermediate $(7=4+3)$ risk. A pretreatment PSA below $10.0 \mathrm{ng} / \mathrm{mL}$ was observed in $73.9 \%$ of the patients. A total of $21 \%$ of the patients had pretreatment PSA values between 10.0 and $20.0 \mathrm{ng} / \mathrm{mL}$. The patients with a favorable intermediate Gleason score comprised $34.7 \%$ in the modified risk level calculation. The median follow-up was 574 days, the mean was 758 days, and the maximum was 2227 days. There were $18(2.2 \%)$ patients diagnosed with BCR. 
Table 1. Demographics of 809 patients. BCR: biochemical recurrence; PSA: prostate specific antigen.

\begin{tabular}{|c|c|c|c|}
\hline & Category & $N$ & Percent \\
\hline \multirow{5}{*}{$\begin{array}{l}\text { Age at diagnosis } \\
\text { (Mean, Range) }\end{array}$} & Under 59 & 60 & 7.4 \\
\hline & $60-69$ & 313 & 38.7 \\
\hline & $70-79$ & 354 & 43.8 \\
\hline & Over 80 & 82 & 10.1 \\
\hline & $70.04(44-100)$ & & \\
\hline \multirow{4}{*}{ T-stage } & $\mathrm{T} 1$ (T1b, T1c) & 537 & 66.4 \\
\hline & $\mathrm{T} 2 \mathrm{a}$ & 135 & 16.7 \\
\hline & $\mathrm{T} 2 \mathrm{~b}$ & 97 & 12.0 \\
\hline & $\mathrm{T} 2 \mathrm{c}+\mathrm{T} 3$ & 40 & 4.9 \\
\hline \multirow{4}{*}{ Gleason score } & Low $(3+3$ or less $)$ & 302 & 37.3 \\
\hline & Favorable intermediate $(7=3+4)$ & 292 & 36.1 \\
\hline & Unfavorable intermediate $(7=4+3)$ & 146 & 18.0 \\
\hline & High $(4+4$ or greater $)$ & 69 & 8.5 \\
\hline \multirow{3}{*}{ Pretreatment PSA } & $\leq 10.0 \mathrm{ng} / \mathrm{mL}$ & 598 & 73.9 \\
\hline & $>10.0$ and $\leq 20.0 \mathrm{ng} / \mathrm{mL}$ & 170 & 21.0 \\
\hline & $>20.0 \mathrm{ng} / \mathrm{mL}$ & 41 & 5.1 \\
\hline \multirow{5}{*}{ Modified risk level } & Gleason score $\leq 6$ and PSA $\leq 10 \mathrm{ng} / \mathrm{mL}$ & 222 & 27.4 \\
\hline & Gleason score $\leq 6$ and PSA $>10$ and PSA $\leq 20$ & 67 & 8.3 \\
\hline & Gleason score $=7(3+4)$ & 281 & 34.7 \\
\hline & Gleason score $=7(4+3)$ & 142 & 17.6 \\
\hline & Gleason Score $\geq 8$ or PSA $>20$ & 97 & 12.0 \\
\hline \multirow{2}{*}{$\mathrm{BCR}$} & No BCR & 791 & 97.8 \\
\hline & BCR & 18 & 2.2 \\
\hline \multirow{4}{*}{ Follow-up periods } & Median & \multirow{3}{*}{\multicolumn{2}{|c|}{$\begin{array}{l}574 \text { days } \\
758 \text { days } \\
2227 \text { days }\end{array}$}} \\
\hline & Mean & & \\
\hline & Maximum & & \\
\hline & Total & 809 & 100 \\
\hline
\end{tabular}

\subsection{Factors Associated with BCR after SBRT}

Before developing the PCO classifier application, we tested various factors associated with BCR in patients who had received SBRT for prostate cancer (Table 2). Age at diagnosis was a significant factor (for $p<0.01$ ) associated with BCR based on multivariate analysis $(p=0.006)$. The modified risk level had no significant associations with BCR based on multivariate analysis $(p=0.052)$.

Table 2. Cox multivariable regression analysis on BCR.

\begin{tabular}{cccc}
\hline Variables & HR & $\mathbf{9 5 . 0 \%}$ CI & $p$ \\
\hline Age at diagnosis & 2.62 & $1.326-5.166$ & $0.006^{* *}$ \\
T-stage & 1.03 & $0.643-1.641$ & 0.910 \\
Modified risk level & 1.47 & $0.997-2.154$ & 0.052 \\
\hline \multicolumn{5}{c}{$p<0.01}$.
\end{tabular}

\subsection{The PCO Classifier Application}

We calculated the PCO classifier score based on the nomogram depicted in Figure 1 and the data shown in Table 3. The total PCO classifier score was calculated as the sum of the values for each variable. The total scores ranged from 0 to 156 . 


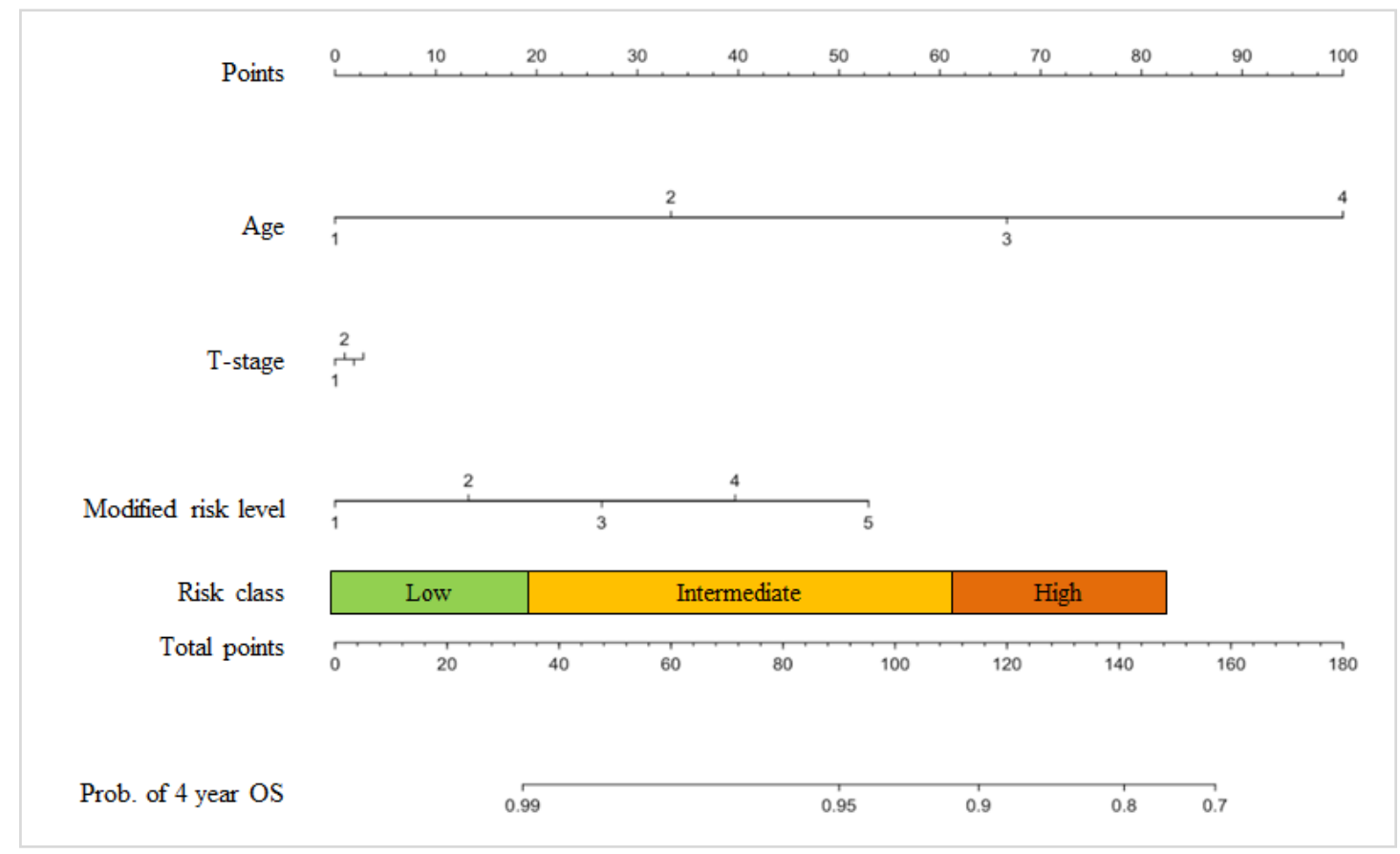

Figure 1. PCO nomogram. Age (years): $1=$ under 59, $2=60-69,3=70-79$, and $4=$ over 80; T-stage: $1=\mathrm{T} 1$ (T1b, T1c), $2=\mathrm{T} 2 \mathrm{a}, 3=\mathrm{T} 2 \mathrm{~b}$, and $4=\mathrm{T} 2 \mathrm{c}-\mathrm{T} 3$; Modified risk level: $1=$ Gleason score $\leq 6$ and $\mathrm{PSA} \leq 10 \mathrm{ng} / \mathrm{mL}, 2=$ Gleason score $\leq 6$ and PSA $>10$ and PSA $\leq 20,3=$ Gleason $=7(3+4)$, $4=$ Gleason $=7(4+3)$, and $5=$ Gleason score $\geq 8$ or PSA $>20$; Nomogram points: Low risk $=0-34$, Intermediate risk $=35-115$, High risk $=116-156$, and Total scores $=0 \sim 156$. Prob. $=$ probability.

Table 3. Prostate Clinical Outlook (PCO) classifier application score.

\begin{tabular}{ccc}
\hline & Variables & Score \\
\hline \multirow{4}{*}{ Age at diagnosis } & Under 59 & 0 \\
& $60-69$ & 33 \\
& $70-79$ & 67 \\
Over 80 & 100 \\
\hline T-stage & T1 (T1b, T1c) & 0 \\
& T2a & 1 \\
T2b & 2 \\
T2c-T3 & 3 \\
\hline Modified risk level & Gleason score $\leq 6$ and PSA $>10$ and PSA $\leq 20$ & 0 \\
& Gleason score $=7(3+4)$ & 26 \\
& Gleason score $=7(4+3)$ & 40 \\
& Gleason score $\geq 8$ or PSA $>20$ & 53 \\
\hline
\end{tabular}

PSA: pretreatment PSA.

The patients were classified using a total score range that was based on the BCR-free survival rate at 4 years: $99 \%, 90 \%$, and $80 \%$. The total scores ranged from 0 to 156 . The PCO classifier application categorized prostate cancer patients into three risk-groups based on the BCR-free survival rate at 4 years: 137 patients were low risk $(16.9 \%)$; 570 patients were intermediate risk $(70.5 \%)$; and 102 patients were high risk (12.6\%). We defined scores of $0-34$ as a low-risk group, scores of 35-115 as an intermediate-risk group, and scores of 116-156 as a high-risk group.

The classifier calibration was assessed by grouping patients by their PCO classifier score (Figure 2). The calibration of the PCO classifier application illustrates how its predictions compare with the actual outcomes for the 809 patients. The performance of the PCO classifier application was within 10\% of the actual outcomes and more accurate at $90 \%$ predicted probability. The $x$-axis is the predicted value 
calculated using the PCO classifier application, and the $y$-axis is the actual freedom from BCR for the present patients $[10,25]$. The vertical bars represent $95 \% \mathrm{CI}$ based on bootstrap analysis.

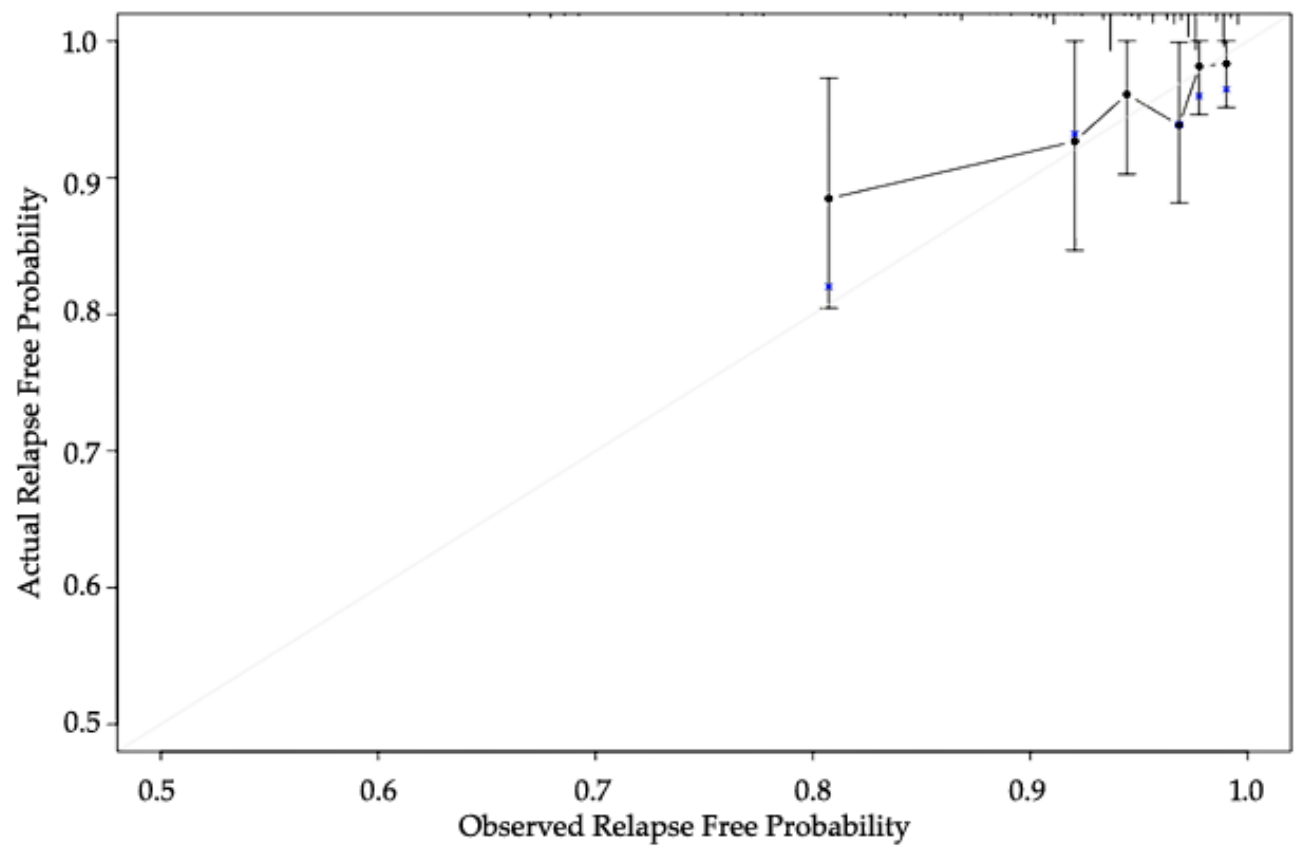

Figure 2. Calibration of the PCO classifier application.

Finally, we validated the PCO classifier application in two steps. First, we used the c-index for accuracy, which indicates the discrimination ability of prediction models [26]. The accuracy of the PCO classifier application was also assessed with Harrell's concordance. Next, we compared the PCO classifier and two other classifiers: Kattan nomogram and D'Amico (Figure 3). The c-index of the PCO classifier was 0.75 (training set) and 0.67 (validation set). The c-index of the Kattan nomogram classifier was 0.62 and 0.63 , respectively, and the c-index of the D'Amico classification was 0.64 and 0.64 , respectively (Table 4).

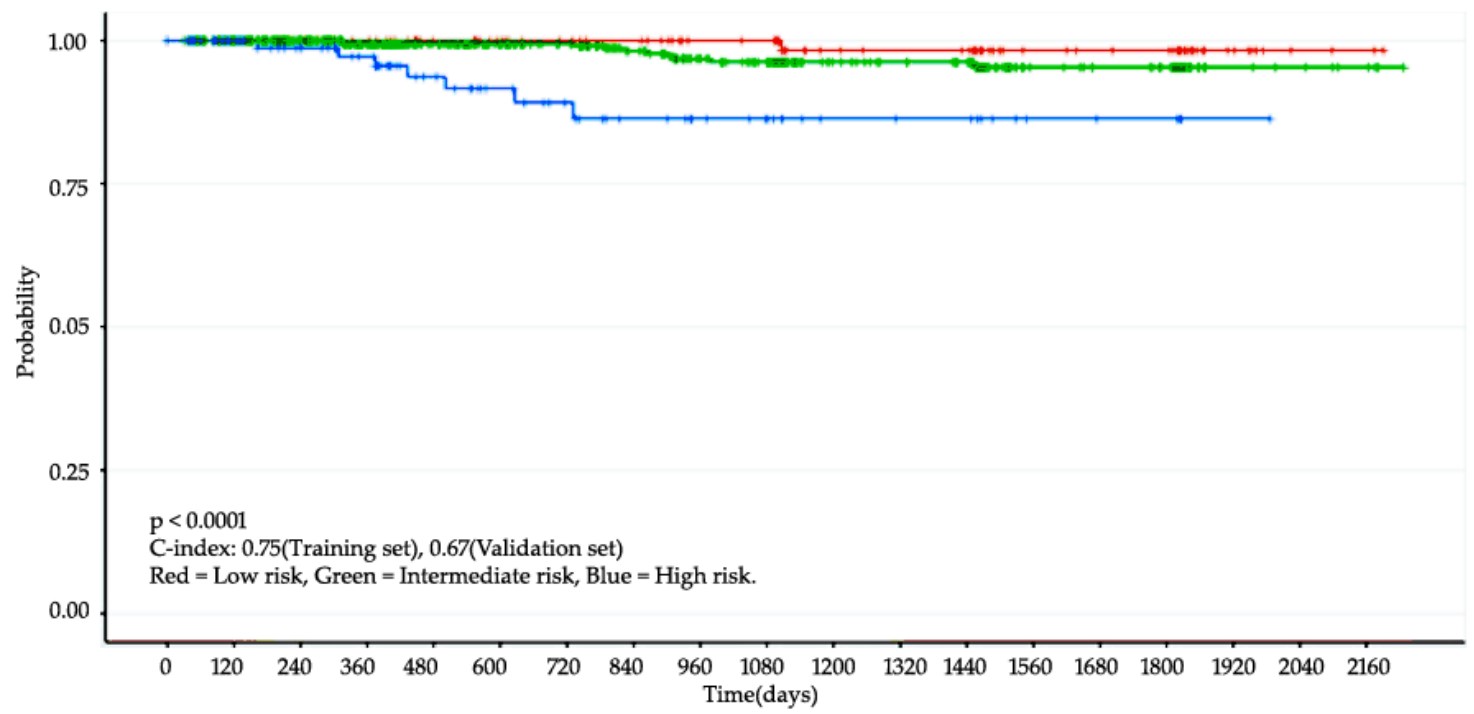

(A) BCR according to PCO classifier

Figure 3. Cont. 


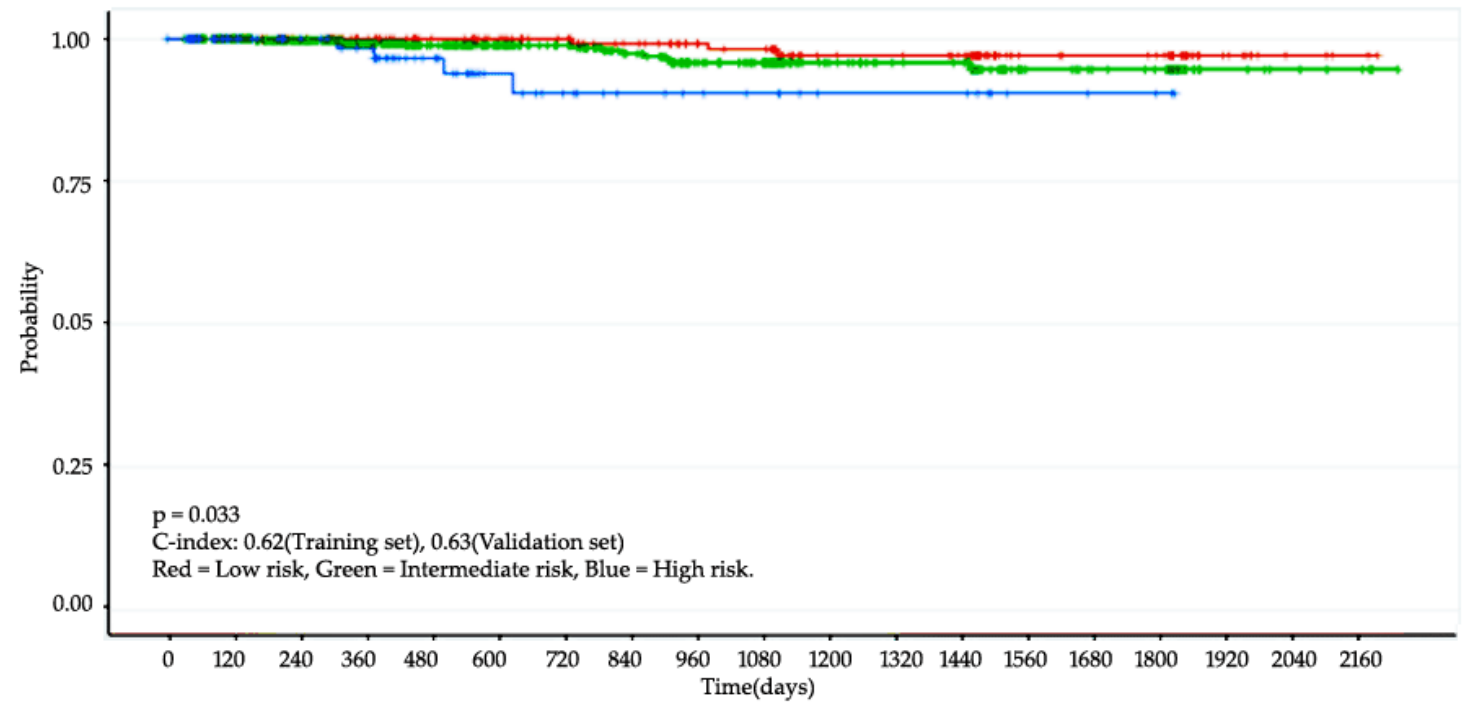

(B) BCR according to the Kattan nomogram classification

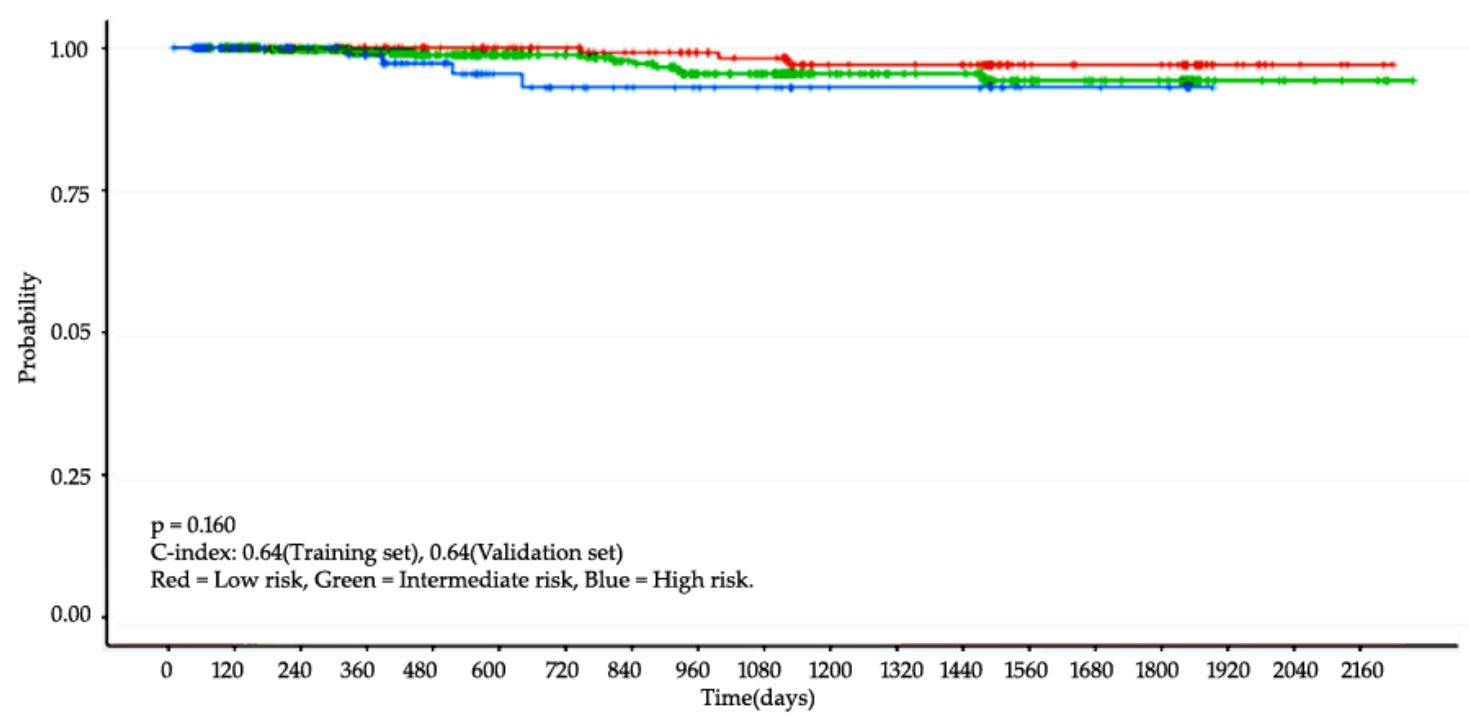

(C) BCR according to the $\mathrm{D}^{\prime}$ Amico classification

Figure 3. $B C R$ (Kaplan-Meier Curve). $N=809$, Confidence interval $=95 \%$.

Table 4. Risk assessments comparison.

\begin{tabular}{|c|c|c|c|c|c|c|}
\hline No. & $\begin{array}{c}\text { Risk } \\
\text { Assessments }\end{array}$ & $\begin{array}{l}\text { Predictor } \\
\text { Variables }\end{array}$ & Treatments & Outcome & Samples & $\begin{array}{l}\text { Performance } \\
\text { (c-Index) }\end{array}$ \\
\hline 1 & $\begin{array}{l}\text { PCO Classifier } \\
\text { Application }\end{array}$ & $\begin{array}{l}\text { Age, Clinical stage, } \\
\text { A modified risk } \\
\text { level (Gleason score } \\
\text { + pretreatment PSA) }\end{array}$ & $\begin{array}{l}\text { Stereotactic body radiation } \\
\text { therapy }\end{array}$ & $\begin{array}{l}\text { Biochemical } \\
\text { recurrence }\end{array}$ & 809 & $\begin{array}{l}0.75^{\mathrm{a}} \\
0.67^{\mathrm{b}}\end{array}$ \\
\hline 2 & $\mathrm{D}^{\prime}$ Amico & $\begin{array}{l}\text { PSA, } \\
\text { Gleason scores, } \\
\text { Clinical stage }\end{array}$ & $\begin{array}{l}\text { Radical Prostatectomy, } \\
\text { External Beam Radiation } \\
\text { Therapy, Interstitial } \\
\text { Radiation Therapy }\end{array}$ & PSA failure & 1872 & $\begin{array}{l}0.62^{a}, \\
0.63^{b}\end{array}$ \\
\hline 3 & Kattan-nomogram & $\begin{array}{c}\text { PSA, } \\
\text { Gleason scores, } \\
\text { Clinical stage }\end{array}$ & Radical prostatectomy & $\begin{array}{l}\text { PSA } \\
\text { recurrence }\end{array}$ & 996 & $\begin{array}{l}0.64^{\mathrm{a}} \\
0.64^{\mathrm{b}}\end{array}$ \\
\hline
\end{tabular}


According to the PCO classifier application, the 5-year BCR-free survival rates for these groups were: low-risk group-98.3\%; intermediate-risk group-95.4\%; and high-risk group- $86.4 \%$. For the entire cohort, the BCR-free survival rate at 5 years was $95.0 \%$.

\section{Discussion}

We developed a PCO classifier application to inform patients electing to undergo prostate cancer treatment with SBRT of potential outcomes. We can draw several conclusions based on our findings.

The PCO classifier application outperforms the D'Amico and Kattan nomogram definitions for the evaluated endpoint of BCR at 5 years post-treatment. We compared recurrence risk analysis and observed c-indexes of 0.75 (training set) and 0.67 (validation set) for the PCO classifier application, 0.62 (training set) and 0.63 (validation set) for Kattan nomogram, and 0.64 (training set) and 0.64 (validation set) for $\mathrm{D}^{\prime}$ Amico. The c-index ranges from 0.5 (equivalent to equal change) to 1.0 (perfect ability to discriminate) [10]. In general, the range of c-index values for prostate cancer is approximately $0.65-0.85$ [11]. The PCO classifier application had a higher prognostic power than the other classifications examined. Accordingly, the PCO classifier application is suitable for predicting BCR in patients undergoing SBRT (Table4).

The PCO classifier application divides patients into three risk-groups based on total PCO classifier scores, ranging from 0 to 156 points. The 5-year BCR-free survival rates for our sample were as follows: 98.3\% for the low-risk group, $95.4 \%$ for the intermediate-risk group, and $86.4 \%$ for the high-risk group. Previous investigations based on risk groups receiving SBRT reported 5-year BCR-free survival rates of the following: $93 \%-97 \%$ for low-risk groups, $86.2 \%-92 \%$ for intermediate-risk groups, and $74.1 \sim 80 \%$ for high-risk groups $[6,16,27]$. Based on the Kattan nomogram definition, the reported 5-year BCR-free survival rate was $95 \%$ for low risk, $90 \%$ for the intermediate risk, and $80 \%$ for high risk [27]. Our 5-year BCR-free survival rates are specific for prostate cancer patients treated with SBRT, while the others include patients treated with radical prostatectomy, external beam radiation therapy, and interstitial radiation therapy [9-12].

To generate a PCO classifier score, the PCO classifier application uses age at diagnosis, which is differently reported depending on the study. Age at diagnosis has been reported to predict BCR for prostate cancer [2,28]. Some classifiers, such as the D'Amico and Kattan nomogram recurrence risk groups, do not use age to predict BCR. D'Amico and Kattan nomogram use PSA, Gleason scores, and clinical stage as predictors of outcomes $[9,10]$. Others, such as the CAPRA score and the Candiolo classifier, use age as a predictor of outcomes. For the PCO classifier application, we decided to use age at diagnosis as a predictor of BCR based on one physician's comments. In addition, we observed that using this variable increased the predictive power of the PCO classifier application. In our results, age at diagnosis did correlate with biochemical outcomes after SBRT using the CyberKnife.

The PCO classifier application employs a modified risk level—a combination of pretreatment PSA and Gleason score- to increase the predictive power of the model. The modified risk level was revised for the PCO classifier application based on Katz's (2013) risk assessment [16]. While the modified risk level is not statistically significant in our results at a $p$-value of 0.05 , the relationship is in the direction we predicted, and the effect size is substantial, providing an interesting finding. Thus, the modified risk level is able to segregate based on established risk assessment criteria, and it increased the prognostic power of the PCO classifier application.

We identify several potential limitations in our work. First, personalized medicine and molecular imaging are emerging approaches to improve the accuracy of traditional prediction methods. These could provide patients with a more personalized risk assessment of clinically relevant outcomes. Future research needs to use diverse factors and variables to predict treatment outcomes. Second, we used only three predictors for the PCO classifier application: (1) age at diagnosis, (2) clinical-radiological staging, and (3) the modified risk level, which is combination of pretreatment prostate specific antigen (PSA) and the Gleason score. We chose to use only these three predictors because the PCO classifier application aimed to calculate the risk using minimal, necessary information 
to support prostate cancer patients' decisions on treatment. In addition, classifiers, such as the CAPRA score and the Candiolo classifier, require positive cores at biopsy as a predictor of BCR. We did not use biopsies as a predictor for the PCO classifier application. Our model can be extended to use other predictors if they are identified as necessary or potentially advantageous to the model's accuracy. Future research should be conducted to include other predictors. Third, 809 patients treated with SBRT and followed for 5 years at a single institution were included in this study. Future research should compare the results using data from other hospitals or a longitudinal observational database, such as the Cancer of the Prostate Strategic Urological Research Endeavor (CaPSURE) database, with various stages and treatments of the prostate [29]. Fourth, we used the ASTRO definition for BCR, even though other research has emphasized that the Phoenix definition is a superior predictor of patient outcomes, such as distant metastasis, cause-specific mortality, and overall mortality [30]. We stand by our decision to use the ASTRO definition, because it is a predictor of distant metastasis and cause-specific mortality, just not overall mortality [30]. The ASTRO definition has resulted in substantially higher estimates of BCR at 5 years than has the Phoenix definition [22]. Because our study was interested in BCR, the ASTRO definition seemed like the correct choice, even if it is controversial. Future research should substitute the Phoenix definition for the ASTRO definition and compare the results. Finally, there are 18 prostate cancer patients with BCR in our study. We developed the PCO classifier application based on 18 patients among 809 patients. The BCR rate in this study is an un-meditated rate. It is a real $\mathrm{BCR}$ rate. However, a future study could collect big data from multiple hospitals to use more patients with BCR.

\section{Conclusions}

The PCO classifier application predicts BCR in patients undergoing SBRT, and we have developed the prostate clinical outlook visualization system (PCOVS) based on the PCO classifier application [13]. Age at diagnosis, clinical-radiological staging, pretreatment PSA, and Gleason scores are important components for predicting BCR after SBRT. The PCO classifier application has the potential to be a tool for employing readily available parameters to stratify prostate cancer patients and to predict probabilities of BCR after SBRT.

Author Contributions: S.K.M. was involved in the study design, revision of the PCO classifier, and revision of the manuscript, and was a major contributor to the study. M.J.R. was involved in the study design, writing of the manuscript, and interpretation of results, and was a major contributor to the development of the PCO classifier. J.P. was involved in the study design, development of the PCO classifier, and writing of the manuscript. S.P.C. and S.S. were involved in the collection of the data, chart review, and interpretation of data. A.D. was involved in the interpretation of the PCO classifier and revision of the manuscript and was a major contributor to the study design. I.Y.C. was involved in the study design.

Funding: Accuray Inc. provided a grant to SPC to support a data manager for CyberKnife SBRT treated patients.

Acknowledgments: The authors would like to acknowledge all the patients.

Conflicts of Interest: Sean P. Collins is a clinical consultant for Accuray Inc. and receives an educational grant to fund a research coordinator in the Department of Radiation Medicine at Georgetown University Hospital. The other authors declare that they have no conflicts of interests.

Ethics Approval: This study follows the IRB regulations of the Georgetown University Medical Center (protocol 12-1175).

Availability of Data and Materials: Please contact the authors for the data request. The visualization software has been published as open source code under an Apache 2.0 license, and it available at OSEHRA.ORG.

Appendix A. Referenced Risk Assessment

\begin{tabular}{cc}
\hline Classification & Criteria [16] \\
\hline Low & Gleason score $\leq 6$ and PSA $\leq 10 \mathrm{ng} / \mathrm{mL}$ \\
Intermediate & Gleason score $=7$ or PSA $>10$ and PSA $\leq 20$ \\
High & Gleason score $\geq 8$ or PSA $>20$ \\
\hline
\end{tabular}


Appendix B. PCO Classifier and Cutoff of Total Score

\begin{tabular}{cccccc}
\hline $\begin{array}{c}\text { Prob. of 4-Year } \\
\text { BCR-Free Rate }\end{array}$ & $\begin{array}{c}\text { Cutoff of } \\
\text { Total Score }\end{array}$ & $\begin{array}{c}\text { Range of Total } \\
\text { Score }\end{array}$ & PCO Class & N & $\%$ \\
\hline $99 \%$ & 34 & $0-34$ & Low & 137 & 16.9 \\
$90 \%$ & 115 & $35-115$ & Intermediate & 570 & 70.5 \\
$80 \%$ & 141 & $116-156$ & High & 102 & 12.6 \\
\hline
\end{tabular}

Appendix C. Life Table of BCR

\begin{tabular}{cccccc}
\hline \multirow{2}{*}{ PCO Class } & \multicolumn{5}{c}{ bRFS (Biochemical Relapse Free Survival) } \\
\cline { 2 - 6 } & $\mathbf{1}$ & $\mathbf{2}$ & $\mathbf{3}$ & \multicolumn{2}{c}{ Rates-Follow-Up (Years) } \\
\hline Low & 100.0 & 100.0 & 100.0 & 98.3 & $\mathbf{5}$ \\
Intermediate & 99.5 & 99.5 & 96.3 & 96.3 & 95.4 \\
High & 97.2 & 89.2 & 86.4 & 86.4 & 86.4 \\
\hline
\end{tabular}

\section{Appendix D. The PCO Classifier Table with Patients' Scores}

\begin{tabular}{|c|c|c|c|c|c|}
\hline \multirow{2}{*}{ Modified Risk Level } & \multirow{2}{*}{ Clinical Stage } & \multicolumn{4}{|c|}{ Age at Diagnosis } \\
\hline & & Under 50 & $60-69$ & $70-79$ & Over 80 \\
\hline \multirow{4}{*}{$\begin{array}{l}\text { Gleason score } \leq 6 \text { and } \\
\text { PSA } \leq 10 \mathrm{ng} / \mathrm{mL}\end{array}$} & $\mathrm{T} 1$ & 0 & 33 & 67 & 100 \\
\hline & $\mathrm{T} 2 \mathrm{a}$ & 1 & 34 & 68 & 101 \\
\hline & $\mathrm{T} 2 \mathrm{~b}$ & 2 & 35 & 69 & 102 \\
\hline & $\mathrm{T} 2 \mathrm{c}-\mathrm{T} 3$ & 3 & 36 & 70 & 103 \\
\hline \multirow{4}{*}{$\begin{array}{c}\text { Gleason score } \leq 6 \text { and } \\
\text { PSA }>10 \text { and PSA } \leq 20\end{array}$} & $\mathrm{~T} 1$ & 13 & 46 & 80 & 113 \\
\hline & $\mathrm{T} 2 \mathrm{a}$ & 14 & 47 & 81 & 114 \\
\hline & $\mathrm{T} 2 \mathrm{~b}$ & 15 & 48 & 82 & 115 \\
\hline & $\mathrm{T} 2 \mathrm{c}-\mathrm{T} 3$ & 16 & 49 & 83 & 116 \\
\hline \multirow{4}{*}{ Gleason score $=7(3+4)$} & T1 & 26 & 59 & 93 & 126 \\
\hline & $\mathrm{T} 2 \mathrm{a}$ & 27 & 60 & 94 & 127 \\
\hline & $\mathrm{T} 2 \mathrm{~b}$ & 28 & 61 & 95 & 128 \\
\hline & $\mathrm{T} 2 \mathrm{c}-\mathrm{T} 3$ & 29 & 62 & 96 & 129 \\
\hline \multirow{4}{*}{ Gleason score $=7(4+3)$} & $\mathrm{T} 1$ & 40 & 73 & 107 & 140 \\
\hline & $\mathrm{T} 2 \mathrm{a}$ & 41 & 74 & 108 & 141 \\
\hline & $\mathrm{T} 2 \mathrm{~b}$ & 42 & 75 & 109 & 142 \\
\hline & $\mathrm{T} 2 \mathrm{c}-\mathrm{T} 3$ & 43 & 76 & 110 & 143 \\
\hline \multirow{4}{*}{$\begin{array}{c}\text { Gleason score } \geq 8 \text { or } \\
\text { PSA }>20\end{array}$} & $\mathrm{~T} 1$ & 53 & 86 & 120 & 153 \\
\hline & $\mathrm{T} 2 \mathrm{a}$ & 54 & 87 & 121 & 154 \\
\hline & $\mathrm{T} 2 \mathrm{~b}$ & 55 & 88 & 122 & 155 \\
\hline & $\mathrm{T} 2 \mathrm{c}-\mathrm{T} 3$ & 56 & 89 & 123 & 156 \\
\hline
\end{tabular}

\section{References}

1. Siegel, R.L.; Miller, K.D.; Jemal, A. Cancer statistics, 2016. CA Cancer J. Clin. 2016, 66, 7-30. [CrossRef] [PubMed]

2. $\quad$ DeSantis, C.E.; Siegel, R.L.; Sauer, A.G.; Miller, K.D.; Fedewa, S.A.; Alcaraz, K.I.; Jemal, A. Cancer statistics for African Americans, 2016: Progress and opportunities in reducing racial disparities. CA Cancer J. Clin. 2016, 66, 290-308. [CrossRef] [PubMed]

3. Kurup, G. Cyberknife: A new paradigm in radiotherapy. J. Med. Phys. Assoc. Med. Phys. India 2010, 35, 63. [CrossRef] [PubMed] 
4. Chen, L.N.; Suy, S.; Uhm, S.; Oermann, E.K.; Ju, A.W.; Chen, V.; Hanscom, H.N.; Laing, S.; Kim, J.S.; Lei, S.; et al. Stereotactic body radiation therapy (sbrt) for clinically localized prostate cancer: The georgetown university experience. Radiat. Oncol. 2013, 8. [CrossRef] [PubMed]

5. Townsend, N.C.; Huth, B.J.; Ding, W.; Garber, B.; Mooreville, M.; Arrigo, S.; Lamond, J.; Brady, L.W. Acute toxicity after cyberknife-delivered hypofractionated radiotherapy for treatment of prostate cancer. Am. J. Clin. Oncol. 2011, 34, 6-10. [CrossRef] [PubMed]

6. Freeman, D.E.; King, C.R. Stereotactic body radiotherapy for low-risk prostate cancer: Five-year outcomes. Radiat. Oncol. 2011, 6. [CrossRef] [PubMed]

7. Katz, A.J.; Ashley, R.; Santoro, M.; Diblasio, F. Stereotactic body radiation therapy for low-and low-intermediate-risk prostate cancer: Is there a dose effect? Front. Oncol. 2011, 1, 49. [CrossRef] [PubMed]

8. Kang, J.-K.; Cho, C.K.; Choi, C.W.; Yoo, S.; Kim, M.-S.; Yang, K.; Yoo, H.; Kim, J.H.; Seo, Y.S.; Lee, D.H.; et al. Image-guided stereotactic body radiation therapy for localized prostate cancer. Tumori 2011, 97, 43-48. [CrossRef] [PubMed]

9. D’amico, A.V.; Whittington, R.; Malkowicz, S.B.; Schultz, D.; Blank, K.; Broderick, G.A.; Tomaszewski, J.E.; Renshaw, A.A.; Kaplan, I.; Beard, C.J.; et al. Biochemical outcome after radical prostatectomy, external beam radiation therapy, or interstitial radiation therapy for clinically localized prostate cancer. JAMA 1998, 280, 969-974. [CrossRef] [PubMed]

10. Rouprêt, M.; Hupertan, V.; Comperat, E.; Drouin, S.J.; Phé, V.; Xylinas, E.; Demanse, D.; Sibony, M.; Richard, F.; Cussenot, O. Cross-cultural validation of a prognostic tool: Example of the kattan preoperative nomogram as a predictor of prostate cancer recurrence after radical prostatectomy. BJU Int. 2009, 104, 813-818. [CrossRef] [PubMed]

11. Cooperberg, M.R.; Broering, J.M.; Carroll, P.R. Risk assessment for prostate cancer metastasis and mortality at the time of diagnosis. J. Natl. Cancer Inst. 2009, 101, 878-887. [CrossRef] [PubMed]

12. Gabriele, D.; Jereczek-Fossa, B.A.; Krengli, M.; Garibaldi, E.; Tessa, M.; Moro, G.; Girelli, G.; Gabriele, P. Beyond d'amico risk classes for predicting recurrence after external beam radiotherapy for prostate cancer: The candiolo classifier. Radiat. Oncol. 2016, 11, 23. [CrossRef] [PubMed]

13. Park, J.; Rho, M.J.; Dritschilo, A.; Choi, I.Y.; Mun, S.K. Prostate clinical outlook visualization system for patients and clinicians considering cyberknife treatment-A personalized approach. Appl. Sci. 2018, 8, 471. [CrossRef]

14. Mohler, J.; Armstrong, A.; Bahson, R. National Comprehensive Cancer Network Guidelines: Prostate Cancer Version 1, 2016. J. Natl. Compr. Cancer Netw. 2016, 14, 19-30. [CrossRef]

15. Kim, J.K.; Rho, M.J.; Lee, J.S.; Park, Y.H.; Lee, J.Y.; Choi, I.Y. Improved prediction of the pathologic stage of patient with prostate cancer using the cart-pso optimization analysis in the korean population. Technol. Cancer Res. Treat. 2016. [CrossRef]

16. Katz, A.J.; Santoro, M.; Diblasio, F.; Ashley, R. Stereotactic body radiotherapy for localized prostate cancer: Disease control and quality of life at 6 years. Radiat. Oncol. 2013, 8, 1-8. [CrossRef] [PubMed]

17. Peng, L.; Zhang, H.; Yang, B.; Chen, Y.; Zhou, X. Early stage internet traffic identification using data gravitation based classification. In Proceedings of the 2016 IEEE 14th International Conference on Dependable, Autonomic and Secure Computing, 14th International Conference on Pervasive Intelligence and Computing, 2nd International Conference on Big Data Intelligence and Computing and Cyber Science and Technology Congress (DASC/PiCom/DataCom/CyberSciTech), Auckland, New Zealand, 8-12 August 2016; IEEE: Piscataway, NJ, USA, 2016; pp. 504-511.

18. Valentini, V.; Van Stiphout, R.G.; Lammering, G.; Gambacorta, M.A.; Barba, M.C.; Bebenek, M.; Bonnetain, F.; Bosset, J.F.; Bujko, K.; Cionini, L.; et al. Nomograms for predicting local recurrence, distant metastases, and overall survival for patients with locally advanced rectal cancer on the basis of European randomized clinical trials. J. Clin. Oncol. 2011, 29, 3163-3172. [CrossRef] [PubMed]

19. Cookson, M.S.; Aus, G.; Burnett, A.L.; Canby-Hagino, E.D.; D’Amico, A.V.; Dmochowski, R.R.; Eton, D.T.; Forman, J.D.; Goldenberg, S.L.; Hernandez, J.; et al. Variation in the definition of biochemical recurrence in patients treated for localized prostate cancer: The American urological association prostate guidelines for localized prostate cancer update panel report and recommendations for a standard in the reporting of surgical outcomes. J. Urol. 2007, 177, 540-545. [PubMed] 
20. Cox, J.D.; Grignon, D.J.; Kaplan, R.S.; Parsons, J.T.; Schellhammer, P.F.; Zagars, G.; Zietman, A.; Shipley, W. Consensus statement: Guidelines for psa following radiation therapy. Int. J. Radiat. Oncol. Biol. Phys. 1997, $37,1035-1041$.

21. Thompson, A.; Keyes, M.; Pickles, T.; Palma, D.; Moravan, V.; Spadinger, I.; Lapointe, V.; Morris, W.J. Evaluating the phoenix definition of biochemical failure after $125 \mathrm{i}$ prostate brachytherapy: Can psa kinetics distinguish psa failures from psa bounces? Int. J. Radiat. Oncol. Biol. Phys. 2010, 78, 415-421. [CrossRef] [PubMed]

22. Paller, C.J.; Antonarakis, E.S. Management of biochemically recurrent prostate cancer after local therapy: Evolving standards of care and new directions. Clin. Adv. Hematol. Oncol. HO 2013, 11, 14.

23. Kupelian, P.A.; Mahadevan, A.; Reddy, C.A.; Reuther, A.M.; Klein, E.A. Use of different definitions of biochemical failure after external beam radiotherapy changes conclusions about relative treatment efficacy for localized prostate cancer. Urology 2006, 68, 593-598. [CrossRef] [PubMed]

24. Team, R.C. The R Project for Statistical Computing. 2014. Available online: www.R-project.org/ (accessed on 8 October 2014).

25. Kattan, M.W.; Wheeler, T.M.; Scardino, P.T. Postoperative nomogram for disease recurrence after radical prostatectomy for prostate cancer. J. Clin. Oncol. 1999, 17, 1499. [CrossRef] [PubMed]

26. Harrell, F.E.; Califf, R.M.; Pryor, D.B.; Lee, K.L.; Rosati, R.A. Evaluating the yield of medical tests. JAMA 1982, 247, 2543-2546. [CrossRef] [PubMed]

27. Katz, A.; Freeman, D.; Aronovitz, J.; Fuller, D.; Bolzicco, G.; Meier, R.; Collins, S.; Wang, J.; Steinberg, M.; King, C. Five-year biochemical control rates for stereotactic body radiation therapy for organ-confined prostate cancer: A multi-institutional pooled analysis. Int. J. Radiat. Oncol. Biol. Phys. 2012, 84, S147-S148. [CrossRef]

28. Siddiqui, S.A.; Sengupta, S.; Slezak, J.M.; Bergstralh, E.J.; Leibovich, B.C.; Myers, R.P.; Zincke, H.; Blute, M.L. Impact of patient age at treatment on outcome following radical retropubic prostatectomy for prostate cancer. J. Urol. 2006, 175, 952-957. [CrossRef]

29. Lubeck, D.P.; Litwin, M.S.; Henning, J.M.; Stier, D.M.; Mazonson, P.; Fisk, R.; Carroll, P.R. The capsure database: A methodology for clinical practice and research in prostate cancer. Urology 1996, 48, 773-777. [CrossRef]

30. Abramowitz, M.C.; Li, T.; Buyyounouski, M.K.; Ross, E.; Uzzo, R.G.; Pollack, A.; Horwitz, E.M. The phoenix definition of biochemical failure predicts for overall survival in patients with prostate cancer. Cancer 2008, 112, 55-60. [CrossRef] [PubMed] 